\title{
Estimation of the 2001 Kunlun earthquake fault slip from GPS coseismic data using Hori's inverse method*
}

\author{
Honglin Jin * and Hui Wang \\ Institute of Earthquake Science, China Earthquake Administration, Beijing 100036, China
}

\begin{abstract}
The Hori's inverse method based on spectral decomposition was applied to estimate coseismic slip distribution on the rupture plane of the 14 November $2001 M_{\mathrm{S}} 8.1$ Kunlun earthquake based on GPS survey results. The inversion result shows that the six sliding models can be constrained by the coseismic GPS data. The established slips mainly concentrated along the eastern segment of the fault rupture, and the maximum magnitude is about $7 \mathrm{~m}$. Slip on the eastern segment of the fault rupture represents as purely left-lateral strike-slip. Slip on the western segment of the seismic rupture represents as mainly dip-slip with the maximum dip-slip about $1 \mathrm{~m}$. Total predicted scalar seismic moment is $5.196 \times 10^{20} \mathrm{~N} \cdot \mathrm{m}$. Our results constrained by geodetic data are consistent with seismological results.
\end{abstract}

Key words: Kunlun $M_{\mathrm{S}} 8.1$ earthquake; coseismic GPS data; fault slip; inversion

CLC number: P315.72 5 Document code: A

\section{Introduction}

The 14 November $2001 M_{\mathrm{S}} 8.1$ Kunlun earthquake occurred in the west of Kunlun mountain pass in Qinghai province. It is the largest earthquake that occurred on the east Kunlun fault. The surface rupture produced by the event was the longest one among historical earthquakes. It spans from west of the Hoh Sai Lake to east of the Kunlun mountain pass. The western end of the fault rupture is located near the Buka Daban Peak, and the eastern end of the fault rupture is located $70 \mathrm{~km}$ east of the Kunlun mountain pass. The total length of the fault rupture is about $426 \mathrm{~km}$. The maximum horizontal dislocation along the fault rupture is more than $6 \mathrm{~m}$. The maximum vertical dislocation is less than $1 \mathrm{~m}$ (Xu et al, 2002). The 1973 M7.3 Mayi earthquake, the $1997 M_{\mathrm{S}} 7.5$ Mayi earthquake, the 1937 M7.5 Huashixia earthquake, and the $1963 M_{\mathrm{S}} 7.1$ Dulan earthquake occurred along the east Kunlun fault. The mechanisms of these earthquakes are consistent with local deformation pattern (Shen et al, 2003).

Previous studies have provided plenty of data on the $M_{\mathrm{S}} 8.1$ Kunlun earthquake. The data include dis-

\footnotetext{
${ }^{*}$ Received 20 July 2009; accepted in revised form 30 October 2009; published 10 December 2009.

•Corresponding author. e-mail: jhl@seis.ac.cn
}

placements at more than 40 sites along the fault rupture, the epicenter, the distribution of surface rupture and coseismic GPS data, etc. The research fields include geological investigation, seismometry, level survey and GPS survey, etc. Field investigation found that the maximum surface left-lateral coseismic dislocation is 6-7 $\mathrm{m}$, and the maximum vertical displacement reaches $4 \mathrm{~m}$ (Xu et al, 2002; Chen et al, 2003). However, field investigation just provided data on several sites along the fault rupture, not giving deep slip on the rupture plane. Wan et al $(2004,2008)$ inverted distribution of deep slips on fault plane basing on geodetic data by using Okada's method. In Okada's inverse method, discrete observation data were directly used to estimate slip distribution with some prior information. As a result, the data conditions, such as data density, distribution and accuracy, directly affect inversion results. So, their results are rough and cannot constrain detailed fault slip.

The representation theorem in elastostatics relates surface displacements to slip distribution on a fault surface through a linear integral equation that uses Green's function (Maruyama, 1964; Okada, 1985). Therefore we can set up an inverse problem for reconstructing the static image of a seismic or aseismic source from observed geodetic data. The Hori's inverse method that based on a spectral decomposition of the Green's func- 
tion, is similar to the SVD (singular-value decomposition) analysis method (Menke, 1984; Parker, 1977, 1994 Kirsch, 1996). As a continuous inverse method, the Hori's method separates the inverse into two steps: firstly calculate an inverse operator based on given domains of surface and fault structure; and secondly estimate the slip distribution from observed data. Moreover, the method does not require any prior information about the smoothness of fault slip distribution since it assumes that the response function and source function are intrinsically smooth.

In order to get detailed slip distribution function on fault plane, we will apply Hori's method to invert the coseismic slip distribution using observed GPS data. First, we introduce the inverse analysis method, then, invert the coseismic slip distribution of 2001 Kunlun earthquake using coseismic GPS data. Finally, we discuss the tectonic implication of our results.

\section{Inversion method based on a spectral decomposition of Green's function}

We assume the medium to be an elastic half-space. Let $\boldsymbol{S}$ be the surface plane and $\boldsymbol{F}$ be the fault plane, and denote the points on $\boldsymbol{S}$ and $\boldsymbol{F}$ by vectors $\boldsymbol{x}$ and $\boldsymbol{y}$, respectively. According to the representation theorem in elastostatics (Maruyama, 1964; Yabuki and Matsu'ura, 1992), the static surface displacements $\boldsymbol{u}(\boldsymbol{x})$ are expressed as

$$
\boldsymbol{u}(\boldsymbol{x})=\int_{F} g(x, y) p(y) \mathrm{d} y
$$

in terms of source function $\boldsymbol{p}(\boldsymbol{y})$ (slip or back slip) and Green's function. According to function analysis theory, the Green's function $\boldsymbol{g}(\boldsymbol{x}, \boldsymbol{y})$ is regarded as a compact operator that maps from source to response, and the operator admits the spectral decomposition (Hori, 2001)

$$
\boldsymbol{g}(\boldsymbol{x}, \boldsymbol{y})=\sum_{\alpha=1}^{\infty} \lambda^{\alpha} \varphi^{\alpha}(\boldsymbol{x}) \psi^{\alpha}(\boldsymbol{y}),
$$

where $\lambda^{\alpha}$ is the $\alpha$-th eigenvalue, $\varphi^{\alpha}(\boldsymbol{x})$ and $\psi^{\alpha}(\boldsymbol{y})$ are the associated eigenfunctions of the surface and the fault, respectively. The $\alpha$-th eigenvalue is positive value that converges to zero as $\alpha$ increases, and $\varphi^{\alpha}(\boldsymbol{x})$ and $\psi^{\alpha}(\boldsymbol{y})$ form orthonormal basis functions on $\boldsymbol{S}$ and $\boldsymbol{F}$ respectively.

$\boldsymbol{u}(\boldsymbol{x})$ is expressed as a linear combination of the measurable modes $\left\{\varphi^{1}(\boldsymbol{x}), \varphi^{2}(\boldsymbol{x}), \cdots, \varphi^{k}(\boldsymbol{x})\right\}$, and $\boldsymbol{p}(\boldsymbol{y})$ is expressed as the linear combination of source eigenfunctions $\left\{\psi^{1}(\boldsymbol{y}), \psi^{2}(\boldsymbol{y}), \cdots, \psi^{k}(\boldsymbol{y})\right\}$, which are associ- ated with $k$ eigenvalues.

$$
\begin{gathered}
\boldsymbol{u}(\boldsymbol{x})=\sum_{\alpha=1}^{\infty} u^{\alpha} \varphi^{\alpha}(\boldsymbol{x})+\text { noise } \\
\boldsymbol{p}(\boldsymbol{y})=\sum_{\alpha=1}^{\infty} \frac{u^{\alpha}}{\lambda^{\alpha}} \psi^{\alpha}(\boldsymbol{y})
\end{gathered}
$$

In above equations, $u^{\alpha}$ are coefficients of $\varphi^{\alpha}(\boldsymbol{x})$, and $k$ is measurable number of the eigenvalues (or modes). The second term in equation (3) contains modes given by $\varphi^{\alpha}(\boldsymbol{x})$ for $\alpha>k$, but they cannot be distinguished from errors or noises due to the limited accuracy. Therefore, even though a response function cannot be measured, it is possible to accurately estimate a continuous function from a set of discrete data by using a set of eigenfunctions. The coefficients $\left\{u^{\alpha}\right\}$ are estimated by numerical computation, generally using the least squares method. Detailed interpretation for the formulation and the parameters used refer to Hori (2001) and Jin et al (2007).

\section{Estimation of back-slip distribution}

\subsection{Surface and fault structure}

First, we determine the domains of the surface and the fault structure. Fault structure is determined from geological results. Referring to previous researches (Chen et al, 2003; Tan et al, 2004; Wan et al, 2004; Xu and Chen, 2004), we take the depth range of the source domain as $0.5-25 \mathrm{~km}$ to fully cover the rupture fault region. The fault rupture length and dip were taken as $390 \mathrm{~km}$ and $86^{\circ}$, respectively.

The surface $\boldsymbol{S}$ and fault $\boldsymbol{F}$ are decomposed into $N$ and $M$ segments. The convergence is checked by increasing $N$ and $M$ which correspond to the discretization for surface and fault. It is important to examine the numerical validity of spectral decomposition. We note that Green's function must be discretized using the $(N, M)$ points by employing a set of smooth functions when spectral decomposition is obtained numerically.

A smoothed fault is plotted on a grid with 2106 elements for numerical computations. In this study, we use the point dislocations embedded in the smoothed curved surface, instead of multi-rectangular fault planes as used in the previous studies.

The Earth's surface is represented by a curved plane of $870 \mathrm{~km} \times 610 \mathrm{~km}$ along the rupture fault and the surface was gridded into 3315 elements for numerical computations. With the selected set of discrete points representing the surface and fault domains (Figure 1), we calculate the Green's function, $\boldsymbol{g}(\boldsymbol{x}, \boldsymbol{y})$, and separate 
it into a set of surface and fault eigenfunctions by spectral decomposition. Note that the surface deformation caused by fault coseismic slip can be expressed by a linear combination of surface eigenfunctions, and then slip distribution is expressed by a linear combination of fault eigenfunctions.

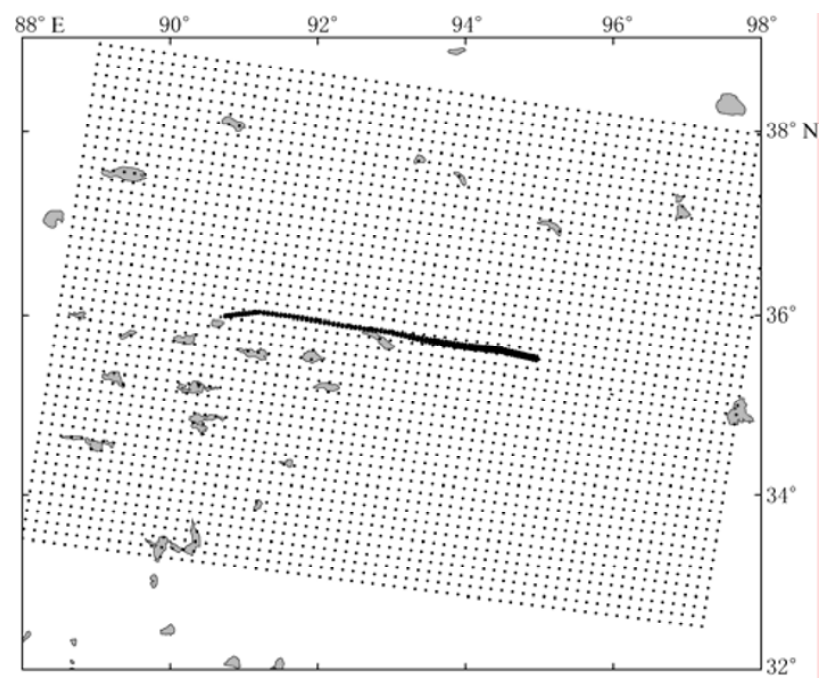

Figure 1 Domain of surface and fault (thick line).

\subsection{GPS data}

The coseismic displacements calculated from GPS measurements indicate that the deformation caused by the 2001 Kunlun $M_{\mathrm{S}} 8.1$ earthquake is within an area of $88^{\circ} \mathrm{E}-97^{\circ} \mathrm{E}$ and $32^{\circ} \mathrm{N}-38^{\circ} \mathrm{N} .58$ old GPS stations at the surface rupture and the surrounding areas were occupied after the earthquake to compare with GPS measurements obtained several years before the earthquake. 16 new stations were also established immediately across the surface rupture after the earthquake. Among them, four GPS sites were observed continuously and the rest sites have been measured six times since 2 December 2001. Combining these data with survey result of earthquake surface rupture, Ren and Wang (2005) obtained the GPS-measured coseismic displacements. In this study, we use the data from 28 GPS stations less than $200 \mathrm{~km}$ away from the fault (Figure 2).

\subsection{Inversion result}

Based on the GPS velocity field shown in Figure 2, the surface displacement function can be estimated from the surface eigenfunctions and coefficients $u^{\alpha}$ given in equation (3). First, in order to seek suitable $k$, stability of the coefficients is studied with GPS data. By increasing $k(k=1,2, \cdots, 25)$ for coefficients $u^{k}$ (Jin et al, 2007), the stability of coefficient is expressed by coefficient changes $\left(u_{i+1}^{\alpha}-u_{i}^{\alpha}\right)$ with different $i(i=1,2, \cdots, 25)$. The smaller coefficient of variation tends to more stable. Figure 3 shows stability of coefficients $u^{1}$ and $u^{2}$, from which we can found the suitable $k$ value with coefficient $u^{k}$ is 6 . If $k>6$, large error resulted from the instable coefficients will be introduced to inversion result. Once $k=6$ is determined, we can estimate the surface displacements function, as shown in Figure 2 (blue). It means the available GPS data can extract slip modes up to 6 for the given fault structure.

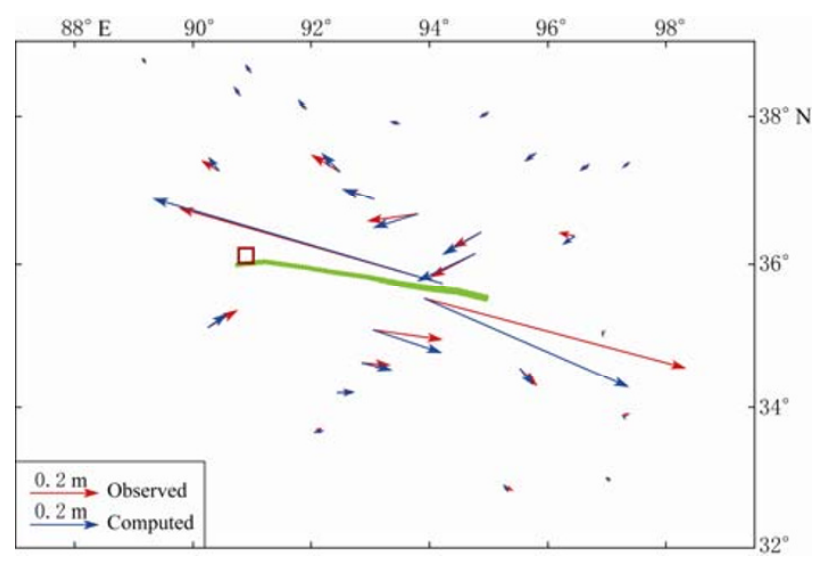

Figure 2 Coseismic horizontal displacement on surface. The square denotes the location of the $M_{\mathrm{S}} 8.1$ Kunlun earthquake given by China Earthquake Networks Center (CENC), which is the same as that in Figures 4, 5 and 6.

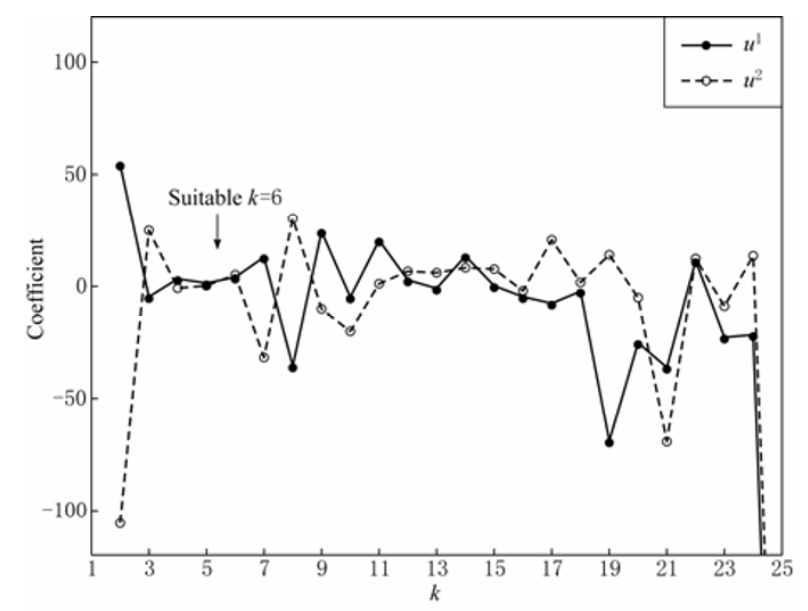

Figure 3 Stability of coefficients $u^{1}$ and $u^{2}$ with variation of mode number $k$.

Figure 2 also shows a comparison between the observed and estimated displacement at GPS stations. Figure 4 and Table 1 show residual displacement by subtracting estimated from observed. Generally speaking, the observed displacements are consistent with the esti- 
Table 1 Residual displacement by subtracting estimated from observed

\begin{tabular}{|c|c|c|c|c|c|}
\hline & Long. $/{ }^{\circ} \mathrm{E}$ & Lat. $/{ }^{\circ} \mathrm{N}$ & $d_{x} / \mathrm{m}$ & $d_{y} / \mathrm{m}$ & $\delta / \mathrm{m}$ \\
\hline 1 & 97.378 & 37.381 & 0.009291194 & 0.009172645 & 0.013056175 \\
\hline 2 & 90.442 & 37.274 & -0.019863578 & -0.010587580 & 0.022509078 \\
\hline 3 & 93.067 & 36.890 & 0.004118366 & 0.000478307 & 0.004146048 \\
\hline 4 & 91.914 & 38.091 & 0.004324020 & -0.016223081 & 0.016789446 \\
\hline 5 & 92.491 & 37.259 & -0.030597294 & -0.004390009 & 0.030910623 \\
\hline 6 & 93.809 & 36.682 & -0.017772811 & 0.019331826 & 0.026260089 \\
\hline 7 & 92.854 & 34.630 & -0.004705684 & 0.015380128 & 0.016083899 \\
\hline 8 & 96.927 & 35.060 & 0.006602382 & 0.017326045 & 0.018541394 \\
\hline 9 & 94.219 & 35.732 & 0.075980556 & -0.027845789 & 0.080922388 \\
\hline 10 & 97.267 & 33.897 & 0.011724018 & 0.015443835 & 0.019389807 \\
\hline 11 & 96.458 & 36.381 & -0.010193507 & 0.034884521 & 0.036343327 \\
\hline 12 & 95.803 & 37.513 & 0.013250169 & 0.010706802 & 0.017035334 \\
\hline 13 & 96.699 & 37.363 & 0.012810234 & 0.003401609 & 0.013254171 \\
\hline 14 & 94.998 & 38.057 & 0.010868880 & 0.003117267 & 0.011307073 \\
\hline 15 & 93.499 & 37.902 & 0.009433194 & -0.001395764 & 0.009535896 \\
\hline 16 & 90.804 & 38.287 & 0.003808627 & -0.008672906 & 0.009472325 \\
\hline 17 & 89.196 & 38.717 & 0.004453031 & 0.002384795 & 0.005051409 \\
\hline 18 & 90.260 & 35.122 & 0.030283321 & 0.010344937 & 0.032001520 \\
\hline 19 & 94.772 & 36.145 & 0.038914704 & 0.011952239 & 0.040708846 \\
\hline 20 & 95.528 & 34.552 & 0.012483076 & -0.002884207 & 0.012811942 \\
\hline 21 & 95.257 & 32.893 & 0.013450948 & 0.003448836 & 0.013886054 \\
\hline 22 & 92.438 & 34.207 & 0.000435777 & 0.002226550 & 0.002268794 \\
\hline 23 & 94.873 & 36.433 & 0.028035139 & 0.019130859 & 0.033940518 \\
\hline 24 & 90.982 & 38.588 & 0.004890789 & -0.001973474 & 0.005273937 \\
\hline 25 & 96.988 & 32.997 & 0.004325686 & 0.005349281 & 0.006879416 \\
\hline 26 & 93.052 & 35.088 & 0.000858289 & 0.038753540 & 0.038763043 \\
\hline 27 & 93.913 & 35.520 & 0.166129389 & 0.056926314 & 0.175612013 \\
\hline 28 & 92.056 & 33.649 & -0.005852566 & 0.008345473 & 0.010193108 \\
\hline
\end{tabular}

Note: $d_{x}$ and $d_{y}$ are E-W and N-S component error, respectively; $\delta=\left(d_{x}^{2}+d_{y}^{2}\right)^{1 / 2}$

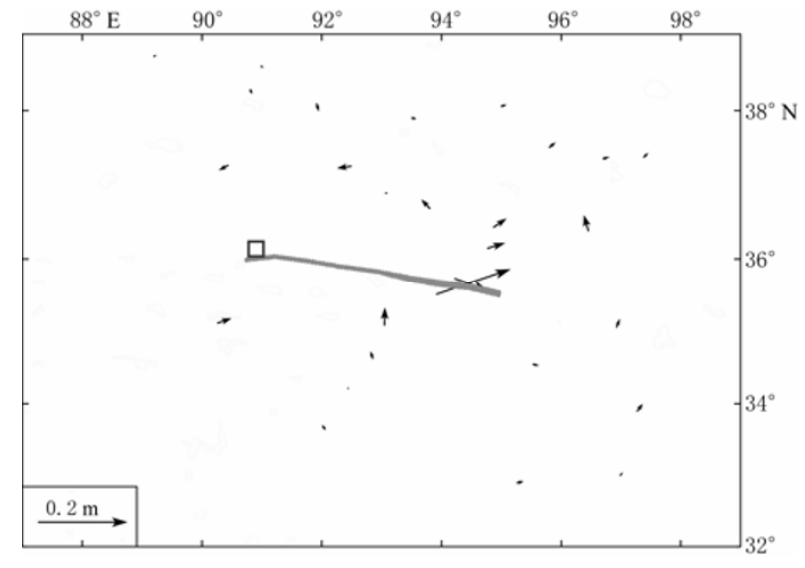

Figure 4 The residual displacement by subtracting estimated from observed.

mated velocities (for $k=6$ ) both in directions and their magnitudes.

The estimated slip distribution along the fault for $k=6$ is shown in Figure 5. The maximum slip of about 7 $\mathrm{m}$ concentrated on the eastern segment of the fault. To the east of $93^{\circ} \mathrm{E}$ slip distribution displayed purely left-lateral strike slip, and dip slip of $1 \mathrm{~m}$ occurred around the western segment.

Figure 6 gives a theoretical calculation result with three components of coseismic displacement on surface. The inverted vertical displacements show that to the west of $93^{\circ} \mathrm{E}$ the southern side of the fault is uplifted, and to the east of $93^{\circ} \mathrm{E}$ the northern side of the fault is uplifted. These results are consistent with other inversion results (Wan et al, 2004, 2008). The released seismic moment estimated by geodetic data is $5.196 \times 10^{20}$ $\mathrm{N} \cdot \mathrm{m}$.

\section{Discussion and conclusions}

The distribution of slips (slip function) on the rupture plane caused by the $M_{\mathrm{S}} 8.1$ Kunlun mountain earthquake was constrained by the coseismic GPS data. The predicted maximum slip is about $7 \mathrm{~m}$, which is close to that of 5-6 m from Tan et al (2004). It is also similar to Wan et al (2008) that indicates the largest slip is $7 \mathrm{~m}$ using GPS and InSAR data. On the other hand, our results are different from the inverted results using digital teleseismic data. The maximum slip estimated by Zhou et al (2004) is $3.6 \mathrm{~m}$, and $2.2 \mathrm{~m}$ by Xu and Chen (2004) and Chen et al (2004). The maximum slip established using GPS data is significantly larger than that derived from the seismic wave data, which may be resulted from GPS data contaminated by postseismic deformation. 


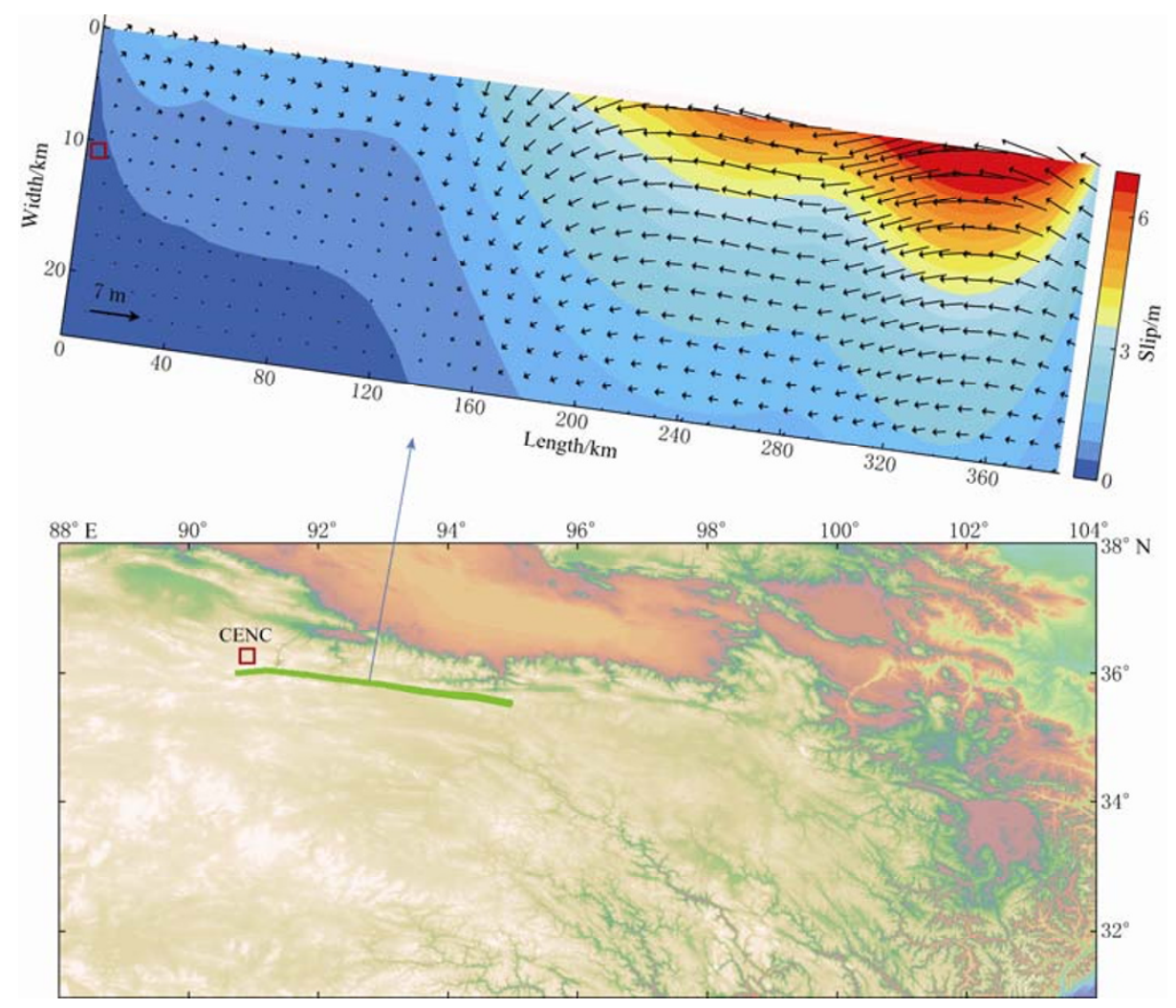

Figure 5 Slip distribution estimated by coseismic displacement data.

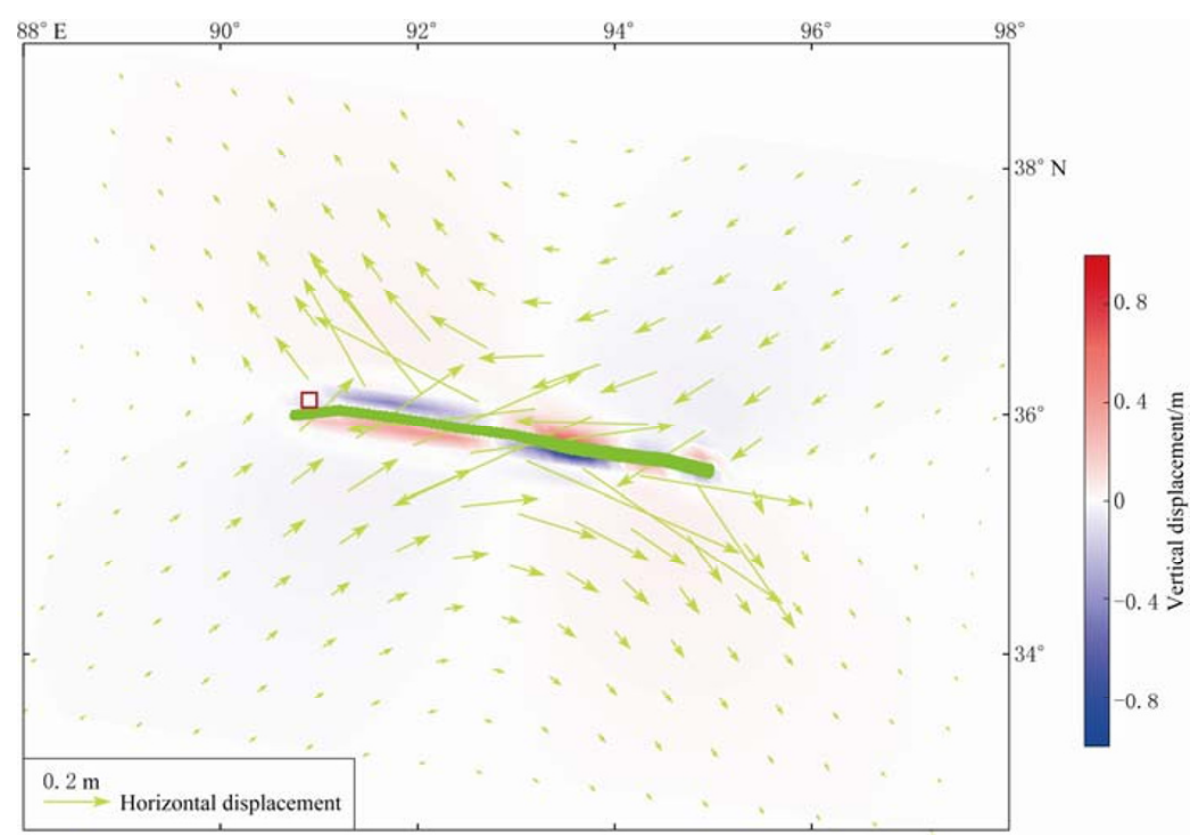

Figure 6 Three components of estimated surface displacements.

Our predicted results show that slips on the western segment of the Kunlun fault rupture are less than those on the eastern segment. It is similar to Wan et al (2008).
The results indicate the strain energy released on the eastern segment is larger than that on the western segment. The different coseismic slip shows that faults in 
the west may still be locked.

Computed total seismic moment is $5.196 \times 10^{20} \mathrm{~N} \cdot \mathrm{m}$ based the predicted slips on the rupture. It is less than results from Harvard centroid moment tensor $\left(5.9 \times 10^{20}\right.$ $\mathrm{N} \cdot \mathrm{m})$ and from Wan et al $(2004,2008)$. This is may be caused by different fault structure (fault dip, depth, length) we used. The different fault structures affect estimated fault slip distribution (Jin et al, 2007). Moreover, the Hori's method is not valid when the fault slip reaches the surface, so we took the fault structure depth as $0.5-25 \mathrm{~km}$ underground in this study. Therefore, further study is needed to discuss the inversion results with different fault structure to determine the optimal structure of the earthquake fault rupture and the corresponding slip distribution.

Because of the sparse distribution of the survey data and the errors of survey data and the fault structure, we constrained only six functions for the slip model. However, the method proposed by Hori (2001) is still useful to constrain coseismic slip on other faults of Chinese mainland.

Hori's method that constrains coseismic deformation using GPS data is an effective way. However, the result relies closely on the density of GPS sites around the fault. The coseismic deformation distribution established using InSAR technology may lead to more useful results.

Acknowledgements This work was supported by Chinese Joint Seismological Science Foundation (A07005), basic research foundation from Institute of Earthquake Science, and State Key Basic Research Development and Programming Project of China (2004CB418403).

\section{References}

Chen J, Chen Y K, Ding G Y, Tian Q J, Wang Z J, Shan X J, Ren J W, Zhao R B and Wang Z C (2003). Surface rupture zones of the 2001 earthquake $M_{\mathrm{S}} 8.1$ west of Kunlun Pass, Northern Qinghai-Xizang Plateau. Quaternary Sciences 23(6): 629-639 (in Chinese with English abstract).
Chen J, Chen Y K, Ding G Y, Wang Z J, Tian Q J, Yin G M, Shan X J and Wang Z C (2004). Surficial slip distribution and segmentation of the 426 $\mathrm{km}$ long surface rupture of the 14 November, 2001, $M_{\mathrm{S}} 8.1$ earthquake on the east Kunlun fault, northern Tibetan Plateau, China. Seismology and Geology 26(3): 9-21 (in Chinese with English abstract).

Hori M (2001). Inversion analysis method using spectral decomposition of Green's function. Geophys J Int 147: 77-87.

Jin H, Kato T and Hori M (2007). Estimation of slip distribution using a new inverse method based on spectral decomposition of Green's function by GPS data. J Geophys Res 112: B07414, doi:10.1029/2004JB003378.

Kirsch A (1996). An Introduction to the Mathematical Theory of Inverse Problem. Springer-verlage, New York, 284pp.

Maruyama T (1964). Statical elastic dislocation in an infinite and semi-infinite medium. Bull Earth Res Inst Tokyo Univ 42: 289-368.

Menke W (1984). Geophysical Data Analysis: Discrete Inverse Theory. Academic Press, London, 289pp.

Okada Y (1985). Surface deformation due to shear and tensile faults in a half-space. Bull Seism Soc Amer 75(4): 1 135-1 154.

Parker R L (1977). Understanding inverse theory. Ann Rev Earth Planet Sci 5: 35-64.

Parker R L (1994). Geophysical Inverse Theory. Princeton University Press, Princeton, New Jersey, 386pp.

Ren J W and Wang M (2005). GPS Measured crustal deformation of the $M_{\mathrm{S}} 8.1$ Kunlun earthquake on November 14th 2001 in Qinghai-Xizang Plateau. Quaternary Sciences 25(1): 34-44 (in Chinese with English abstract).

Shen Z K, Wan Y G, Gan W J, Zeng Y H and Ren Q (2003). Viscoelastic triggering among large earthquakes along the east Kunlun fault system. Chinese J Geophys 46(6): 786-795 (in Chinese with English abstract).

Tan K, Wang Q and Shen C Y (2004). Using geodetic data to inverse co-seismic dislocation of 2001 Kunlun earthquake. Journal of Geodesy and Geodynamics 24(3): 47-50 (in Chinese with English abstract).

Wan Y G, Wang M, Shen Z K, Chen J, Zhang Z S, Wang Q L and Gan W J (2004). Co-seismic slip distribution of the 2001 West of Kunlun Mountain Pass earthquake inverted by GPS and leveling data. Seismology and Geology 26(3): 393-404 (in Chinese with English abstract).

Wan Y G, Shen Z K, Wang M, Zhang Z S, Gan W J, Wang Q L and Sheng Z S (2008). Co-seismic slip distribution of the 2001 Kunlun mountain pass west earthquake constrained using GPS and InSAR data. Chinese J Geophys 51(4): 1 074-1 084 (in Chinese with English abstract).

$\mathrm{Xu} \mathrm{L} \mathrm{S}$ and Chen Y T (2004). November 14, 2001 Kunlun Mountain Pass earthquake space-time rupture process from a global long-period waveform data. Science in China (Series D) 34(3): 256-264 (in Chinese).

Xu X W, Chen W B, Yu G H, Ma W T, Dai H G, Zhang Z J, Chen Y M, He W G, Wang Z J and Dang G M (2002). Characteristic features of the surface ruptures of the Ku Sai Hu (Kunlunshan) earthquake ( $M_{\mathrm{S}} 8.1$ ), Northern Tibetan Plateau, China. Seismology and Geology 24(1): 1-13 (in Chinese with English abstract).

Yabuki T and Matsu'ura M (1992). Geodetic data inversion using a Bayesian information criterion for spatial distribution of fault slip. Geophys $J$ Int 109: $363-375$.

Zhou Y H, Chen Z L and Miao F J (2004). Source process of the 14 November 2001 western Kunlun mountain $M_{\mathrm{S}}=8.1$ earthquake. Acta Seismologica Sinica 17(Suppl.): 9-21. 